\title{
Single and multiple injections of subconjunctival ranibizumab for early, recurrent pterygium
}

This article was published in the following Dove Press journal:

Clinical Ophthalmology

I March 2013

Number of times this article has been viewed

\author{
Volkan Hurmeric' \\ Pravin Vaddavalli' \\ Anat Galor ${ }^{1,2}$ \\ Victor L Perez' \\ Janika San Roman' \\ Sonia H Yoo' \\ 'Bascom Palmer Eye Institute, \\ University of Miami, Miller School \\ of Medicine, Miami, FL, USA; ${ }^{2}$ Miami \\ Veterans Affairs Medical Center, \\ Miami, FL, USA
}

Correspondence: Sonia H Yoo Bascom Palmer Eye Institute, University of Miami, Miller School of Medicine, 900 NW 17th Street, Miami, FL 33।36, USA

Tel +l 3053266322

Fax + I 3053266337

Email syoo@med.miami.edu
Purpose: To assess the effect of single versus multiple subconjunctival ranibizumab injections in patients with an early pterygium recurrence.

Setting: Single-center, academic practice.

Study population: Nine patients with early pterygium recurrence.

Observational procedure: Subconjunctival ranibizumab $(0.5 \mathrm{mg} / 0.05 \mathrm{~mL})$ was administered adjacent to pterygium recurrence. Group $1(n=5)$ received one injection; group $2(n=4)$ received three injections (time points 0,2 , and 4 weeks) with the ability to retreat as needed.

Main outcome measures: Effect of ranibizumab on conjunctival hyperemia and corneal neovascular area over a 6-month follow-up period.

Results: In the single injection group, a decrease in conjunctival hyperemia was noted in all patients on postinjection day 1 . At follow up, hyperemia grade fluctuated, although all patients had less hyperemia than at baseline. In the recurrent injection group, the median number of injections was 8.5 (range 7 to 9) over the 6 months. In spite of the repeated injections, the pattern of conjunctival hyperemia was similar to that of the single injection group. In group 1, corneal neovascularization remained relatively unchanged over the 6-month period in four patients and decreased in one patient by $24 \%$. In group 2 , corneal neovascularization increased in one patient by $39 \%$, remained stable in one patient, and decreased in two patients by $34 \%$ and $44 \%$.

Conclusion: This is the first study to evaluate the role of ranibizumab in the treatment of an early pterygium recurrence and the first to compare multiple versus single injections. Recurrent injections did not appear to be superior to a single injection with regards to conjunctival hyperemia.

Keywords: pterygium, recurrence, ranibizumab, conjunctival hyperemia, corneal neovascularization

\section{Introduction}

Blockade of vascular endothelial growth factor (VEGF) with bevacizumab (Avastin, Genentech, Inc, San Francisco, CA, USA) and ranibizumab (Lucentis, Genentech, Inc, San Francisco, CA, USA) has been increasingly used to treat abnormal vascular conditions of the anterior segment. ${ }^{1-3}$ In the setting of pterygium, anti-VEGF agents have been studied as primary treatments, ${ }^{4-9}$ as perioperative adjuvants, ${ }^{10-14}$ and as treatments for early pterygium recurrences after surgery. ${ }^{15-17}$ Using anti-VEGF therapy for pterygium has biologic plausibility as several studies have demonstrated elevated levels of VEGF in pterygium tissue as compared to normal conjunctivae. ${ }^{18-22}$ Anti-VEGF therapy appears to be well-tolerated, both when used as an isolated treatment for pterygium and when administered in the perioperative setting, with no major safety issues reported..$^{5-8,10,12-17,23}$ 
The clinical efficacy of anti-VEGF agents in the setting of pterygium, however, is not as clear as its safety record. As a medical treatment of primary and recurrent pterygia, some groups reported a decrease in pterygium area after one injection of bevacizumab, ${ }^{5-7}$ while others found no effect with bevacizumab or ranibizumab., ${ }^{412}$ One possible explanation for the conflicting results may be the time period in which the anti-VEGF agents were administered. It is believed that antiVEGF agents are more effective in regressing young blood vessels that are in a growth phase as opposed to more mature vessels. $^{24,25}$ Nevertheless, pterygium age and activity were not controlled for in the aforementioned studies. Studies that focused on early pterygium recurrences, and therefore likely treated younger vessels, generally found favorable outcomes with improvement in conjunctival injection, ${ }^{16}$ slowed growth of fibrovascular tissue, ${ }^{15}$ and facilitated the regression of limbal-conjunctival neovascularization. ${ }^{17}$

Based on these studies, several questions remain with regards to the use of anti-VEGF agents in pterygium. Along with the issue of whether vessel age is an important predictor of response, the appropriate dosing regimen is another topic for which only limited data is available. Regarding bevacizumab, most studies administered one subconjunctival injection at a dose ranging from $1 \mathrm{mg}$ to $3.75 \mathrm{mg} .^{6,7,9,16}$ One study evaluated the effect of multiple injections without limiting the age at which vessels could be treated. ${ }^{8}$ It is therefore not known if one injection is sufficient to halt disease progression or if multiple injections are needed to maintain an effect. Furthermore, due to the cost differential, only one study evaluated the effect of ranibizumab on pterygium area, again without limiting vessel age and with short term follow-up, as patients proceeded to pterygium surgery within 3 days to 2 months after injection. ${ }^{12}$ To address these gaps in the literature, the aim of this study was to prospectively evaluate the effect of a single versus multiple subconjunctival ranibizumab injections in patients with an early pterygium recurrence.

\section{Materials and methods Study population}

Nine patients with a pterygium recurrence (defined as the presence of corneal vessels with concomitant conjunctival hyperemia) were prospectively recruited to participate in the study. Inclusion criteria included: (1) less than 6 months between the diagnosed recurrence and presentation; (2) the ability to provide written informed consent and comply with assessments for the full duration of the study; and (3) an age greater than 18 years. Exclusion criteria included disease related factors such as prior glaucoma surgery in the region of the pterygium, and patient related factors such as pregnancy, women seeking to become pregnant, and lactating women. The University of Miami Institutional Review Board reviewed and approved this study, which was conducted in accordance with the principles of the Declaration of Helsinki. An investigational new drug approval was obtained from the Food and Drug Administration prior to study commencement. The trial was registered with clinicaltrials. gov (number NCT00768963).

\section{Injection information}

Patients were divided into two groups: the first five patients enrolled in the study (group 1) received one subconjunctival injection in the area of the pterygium. The next four patients (group 2) received three subconjunctival injections (at time points 0,2 , and 4 weeks), and thereafter were followed monthly with the ability to treat as needed based on the presence of conjunctival hyperemia or increasing corneal neovascularization. All patients received the injection at the slit lamp using an eyelid speculum, following the application of an anesthetic, povidone iodine 5\%, and antibiotic drops. Ranibizumab $(0.5 \mathrm{mg} / 0.05 \mathrm{~mL})$ was administered subconjunctivally adjacent to the abnormal vessels at the nasal limbus.

\section{Data collection}

All data were obtained via prospective collection and were entered into a standardized computerized database. The data collected included demographic characteristics, clinical examination findings prior to and after ranibizumab injection, subjective patient evaluations, and clinical photographs. Patients in group 1 were seen 1 day, 1 week, 1 month, 3 months, and 6 months after injection. Patients in group 2 were seen 2 weeks and 1 month after injection, and monthly thereafter.

\section{Main outcome measures}

The primary outcome measures were conjunctival hyperemia and blood vessel area in the cornea. The appearance of the conjunctival hyperemia was graded according to the scale developed by Allergan (Pterygium Hyperemia Grading Scale; Allergan, Inc, Irvine, CA, USA).

The corneal blood vessel area was assessed using the following methodology. Digital slit lamp pictures were taken by a Canon EOS 20D digital camera (Canon Inc, Tokyo, Japan) mounted on a BX900 Haag-Streit slit lamp (HaagStreit AG, Koeniz, Switzerland). All images were taken at 
the same magnification and the patients were asked to fixate at the same target. The digital images were captured with a resolution of at least $2544 \times 1696$ pixels. OIS WinStation Slit Lamp ${ }^{\mathrm{TM}}$ software was used to archive the images (Ophthalmic Imaging Systems, Sacramento, CA, USA). Digital slit lamp pictures were analyzed using Photoshop CS4 (Adobe Systems Inc, Berkeley, CA, USA). The same graphical editing procedure was used for all images. Corneal and conjunctival blood vessels were enhanced using the channel mixer and filter functions of the program. Colored and enhanced images were then used to measure the area of corneal neovascularization. This was achieved by first outlining the limbus and the area of corneal neovascularization on the baseline images; the size of the neovascularized area was then measured in terms of pixels as described in a previous publication (Figure 1). ${ }^{26}$ The location of subconjunctival vessels at the baseline visit was used to correct the magnification and fixation errors of the sequential images of each patient. Secondary outcome measures included the occurrence of adverse events, patient subjective observations, and the need for repeat surgery.

\section{Results}

\section{Study population at presentation}

Nine patients were enrolled into the study. The median age at presentation was 56 years (range 39 to 69 years). Seven patients were male; eight pterygia were found in the right eye. All patients were injected within 6 months of the diagnosed pterygium recurrence (range 2 weeks to 5.5 months). Baseline best corrected visual acuity ranged from 20/20 to hand motion.

\section{Conjunctival hyperemia}

In the single injection group (group 1), a decrease in conjunctival hyperemia was noted in all patients on postinjection day 1 (Figure 2). A three-step decrease in hyperemia was seen in one patient, a two-step decrease in hyperemia was seen in two patients, and a one-step decrease was seen

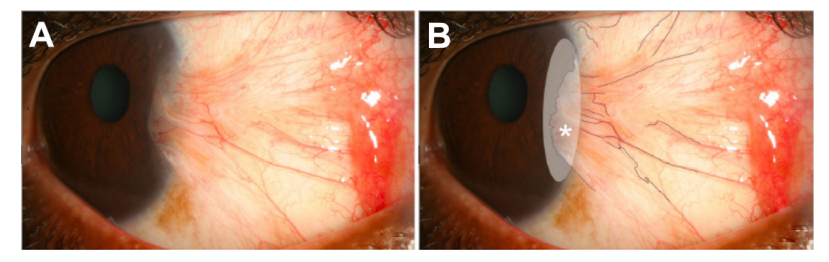

Figure I (A) Slit lamp photograph of a patient before subconjunctival injection. (B) Area of neovascularization (asterisk) was outlined with the software.

Note: The location of the limbus and subconjunctival vessels (grey lines) was marked at the baseline visit. in the remaining two patients. Throughout the follow-up period, hyperemia grade fluctuated in all patients, although all patients had less hyperemia than at baseline. One patient from the single injection group (number 3) reported using adjuvant therapy during this time period in the form of topical fluorometholone for a 1-month period. This patient had a preinjection hyperemia score of 4, and 1-day, 1-week, 1-month, 3-month, and 6-month scores of 2, 1, 1, 1, and 3.

In the recurrent injection group (group 2), the median number of injections over the 6-month follow-up period was 8.5 (range 7 to 9). In spite of the repeated injections, the pattern of conjunctival hyperemia was similar to that seen in the single injection group (Figure 2). All patients had a one-step decrease in their hyperemia grade at 2 weeks; thereafter, the hyperemia continued to fluctuate, but overall appeared less severe than at baseline. One patient from the multiple injection group (number 6) reported using adjuvant topical cyclosporine $0.05 \%$ throughout the study period. This patient had a preinjection hyperemia score of 3, and 1-month, 3-month, and 6-month scores of 1, 1, and 3. Figure 3 depicts patients with an excellent and marginal response to treatment with regards to conjunctival hyperemia.

\section{Corneal neovascularization}

In group 1, four patients demonstrated relatively stable corneal neovascularization over the 6-month period (range $-0.5 \%$ to $+13 \%$ ) (Figure 4 ). One of these four patients (number 5) had an immediate decrease in vessel area followed by slow enlargement to the baseline level by 6 months. The vessel area in one patient (number 4 ) decreased by $24 \%$ over 6 months. In group 2, despite multiple injections, corneal neovascularization increased in one patient (number 9) by $39 \%$. Neovascularization remained stable in one (number 6) and decreased in the remaining two patients by $34 \%$ and 44\% (Figure 5).

\section{Secondary outcome measures}

There were no systemic or local complications associated with the subconjunctival administration of ranibizumab. No patient lost vision after the procedure, with visual acuity being maintained or improved in all. All patients reported a subjective improvement in conjunctival hyperemia starting at day 1 postinjection; however, all noted that the appearance of the pterygium bed fluctuated throughout the study period. Nonetheless, two patients in group 1 and two patients in group 2 stated that they were "completely satisfied" with the treatments, while three patients in group 1 and two patients in group 2 stated that they were "somewhat satisfied." 


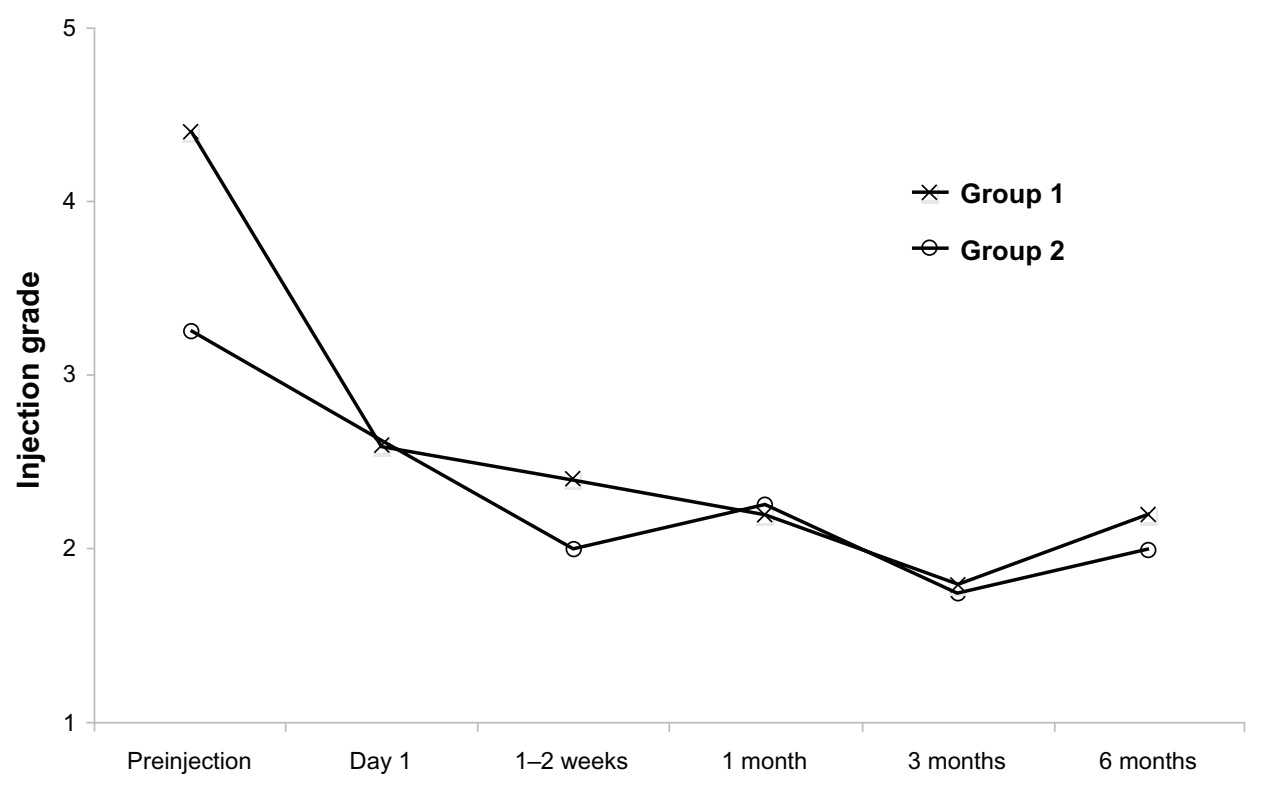

Figure 2 Conjunctival hyperemia scores in patients who received a single subconjunctival ranibizumab injection (group I) and multiple injections (group 2) for a pterygium recurrence (scale 0 to 4 ).

No patients have undergone surgical removal of the pterygium recurrence over the 6-month study period.

\section{Discussion}

This is the first study to evaluate the effects of ranibizumab (as opposed to bevacizumab) in patients with a new pterygium recurrence. In addition, it is the first to evaluate the effects of multiple injections versus a single injection. The rationale behind assessing multiple versus single injections is that multiple injections are often required for a sustained
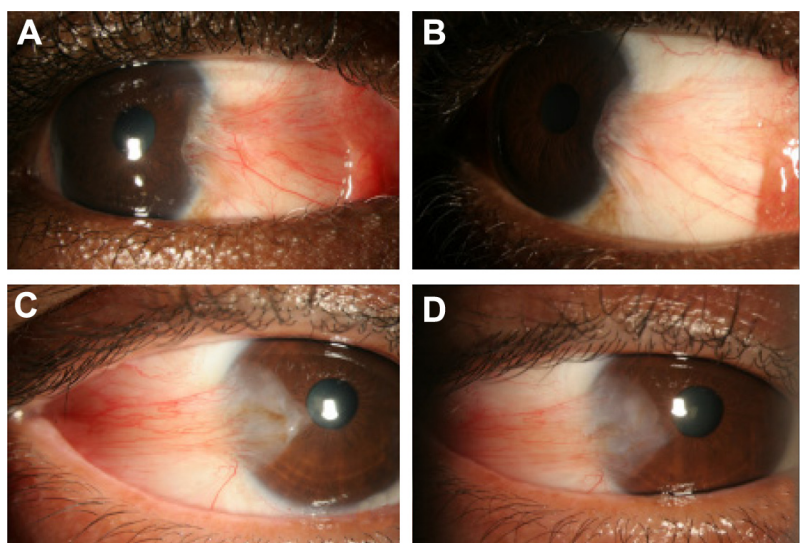

Figure 3 Representative photographs of a patient with significant improvement in conjunctival hyperemia after repeated subconjunctival ranibizumab injections, and photographs of a patient with only mild improvement in conjunctival hyperemia. Representative photographs of a patient with significant improvement in conjunctival hyperemia after repeated subconjunctival ranibizumab injections. (A) Preinjection photograph; (B) postinjection photograph. Representative photographs of a patient with only mild improvement in conjunctival hyperemia after repeated subconjunctival ranibizumab injections. (C) Preinjection photograph; (D) postinjections photograph. effect in age-related macular degeneration. We found that conjunctival hyperemia improved in both groups, without a clear benefit for multiple injections. The effect was not dramatic in either group, and subjective and objective fluctuations were seen throughout the 6-month study period.

With regards to corneal blood vessels, only one patient demonstrated increasing neovascular area (in the recurrent injection group); the blood vessel area in four single injection patients and one recurrent injection patient remained stable at 6 months. One patient in the single injection group and two patients in the recurrent injection group experienced a decrease in area.

Lekhanont et al ${ }^{16}$ likewise focused on early pterygium recurrences and similar to our study, found that subconjunctival bevacizumab resulted in an initial decrease in conjunctival hyperemia scores, with the eventual return of hyperemia to baseline levels by 1 month. Enkvetchakul et al ${ }^{6}$ focused on established primary pterygia and found a sustained reduction in redness scores over 6 months after one injection of bevacizumab. The control group in this study, however, which received one injection of a combination antihistamine/ vasoconstrictor, likewise had reduced redness over this time period although to a lesser degree.

The effect of anti-VEGF therapy on corneal vessels is more difficult to interpret. In our study, eight of nine patients had stable or decreased neovascular area during the follow-up period. Bahar et $\mathrm{al}^{4}$ found no significant change in the percent of vessel area in four patients with recurrent pterygium who received two doses of bevacizumab 1 month 


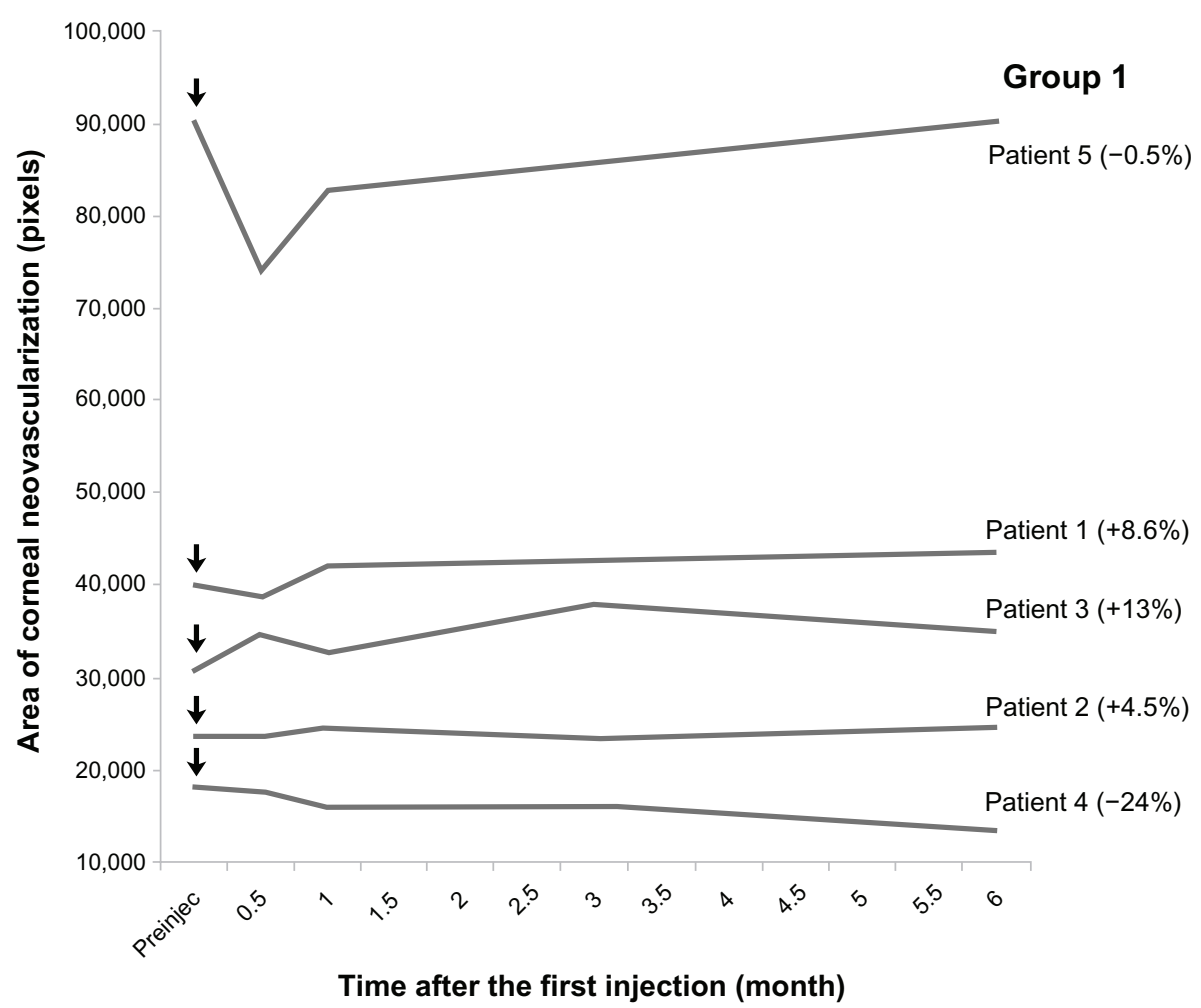

Figure 4 Corneal vessel area at each time point in group I.

Notes: Arrows demonstrate the subconjunctival ranibizumab injection in each patient. Percentages represent changes in the vessel area between 6 months and baseline. Positive values indicate increasing area, while negative numbers indicate decreasing area.

Abbreviation: Preinjec, preinjection.

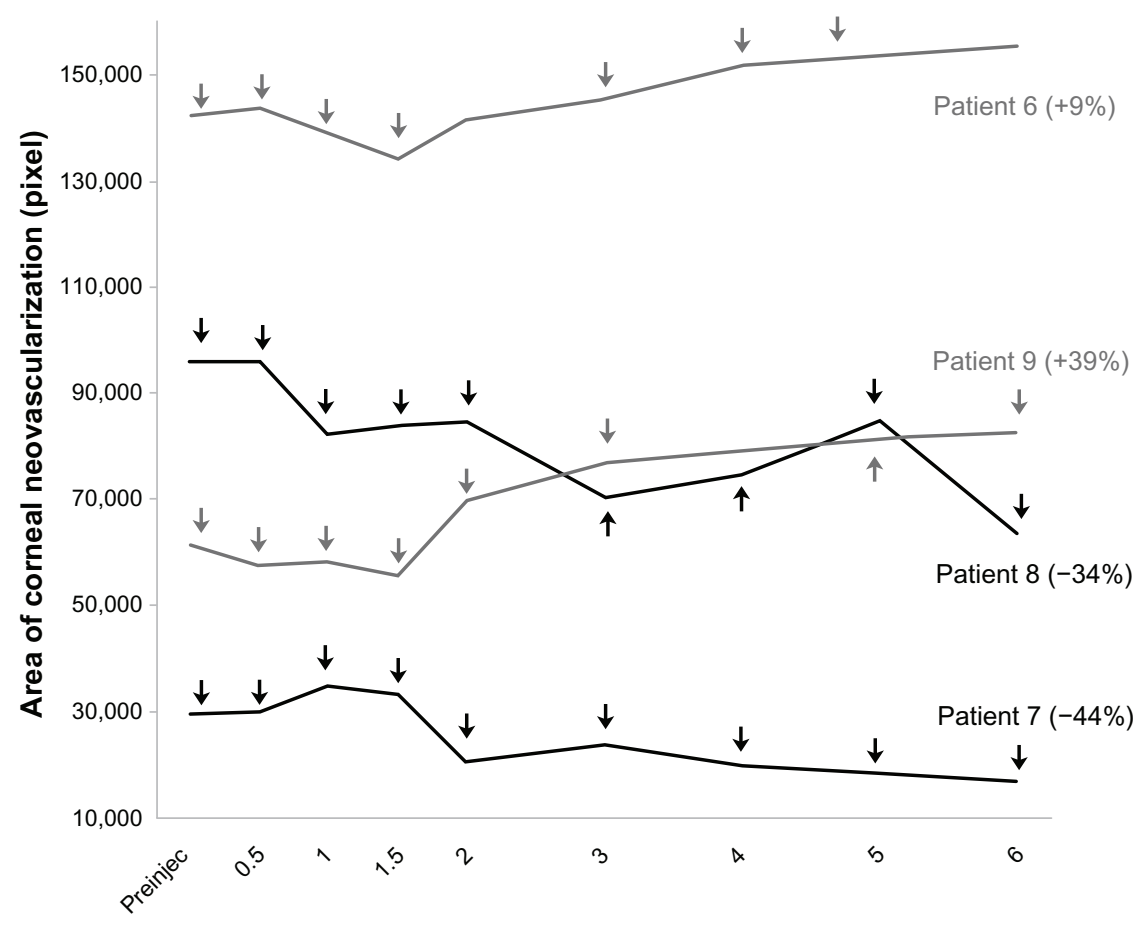

Time after the first injection (month)

Figure 5 Corneal vessel area at each time point in group 2.

Notes: Arrows demonstrate the subconjunctival ranibizumab injections in each patient. Percentages represent changes in the vessel area between 6 months and baseline. Positive values indicate increasing area, while negative numbers indicate decreasing area.

Abbreviation: Preinjec, preinjection. 
apart. Besharati et $a{ }^{5}{ }^{5}$ on the other hand, did report an initial decrease in pterygium size (measured as width and length in $\mathrm{cm}$ ) at 3 months after one injection of bevacizumab in both primary and recurrent pterygium $(n=34)$. Pterygium size at 6 months, however, was not different from baseline. Fallah et $\mathrm{al}^{7}$ similarly reported a decreased percentage of vessel area after one injection of bevacizumab in primary and recurrent pterygium at 3 months $(n=17)$. Six-month follow-up data is not available, however, limiting the ability to evaluate whether the percentage area eventually increased back to preinjection levels.

Several recommendations can be made on the role of antiVEGF therapy in pterygium based on our and earlier studies. Regarding indications for treatment, anti-VEGF therapy appears effective in decreasing conjunctival hyperemia in patients with early and established vessels. ${ }^{6,16}$ One injection of bevacizumab or ranibizumab improved hyperemia up to 6 months with no obvious benefit for scheduled repeat injections. ${ }^{6}$ Based on the cost differential between the two medications (\$50 for $2.5 \mathrm{mg}$ of bevacizumab; $\$ 2000$ for $0.5 \mathrm{mg}$ of ranibizumab) and no clear indication that ranibizumab is superior, bevacizumab is a reasonable first line approach in patients with conjunctival injection. However, it is important to counsel patients that the noted effect may be mild and that fluctuations in hyperemia are expected. Considering the favorable side effect profile of bevacizumab, ${ }^{4-6,16}$ it appears to be a better first line option than a subconjunctival injection of corticosteroid or a vasoconstrictor. As two patients who received multiple injections experienced the greatest reduction in vessel area, we do consider using multiple injections in eyes where active growth of blood vessels is observed on the cornea.

Our recommendations must be considered while bearing in mind our study limitations, which include its small sample size and limited follow-up. However, it is important to consider that in our nine patients who received a total of 40 injections, the medication cost alone limited the number of patients that could be studied. Furthermore, in this study, we did not compare the effects of ranibizumab to other, less costly medications, including topical cyclosporine and bevacizumab. Despite these limitations, in our prospective study, with complete follow-up up to 6 months, we demonstrated no superior role of recurrent injections over a single ranibizumab injection with respect to conjunctival hyperemia. With respect to corneal blood vessels, we found that some patients in both groups had a decrease in vessel area over time, with the effect being greater in the multiple injection group. Future studies will be needed to continue optimizing the indications, dosing, and frequency of anti-VEGF agents in the treatment of abnormal vascular conditions of the ocular surface.

\section{Acknowledgments}

The work was supported by a grant from Genentech; the National Institutes of Health Center Core Grant P30EY014801; Research to Prevent Blindness Unrestricted Grant, Department of Defense (DOD grant number W81XWH-09-1-0675) (institutional grants); VA Career Development Award (Dr Galor). This paper was presented at the Association for Research in Vision and Ophthalmology meeting, Fort Lauderdale, FL, USA, 2011.

\section{Disclosure}

The authors report no conflicts of interest in this work. The authors alone are responsible for the content and writing of the paper.

\section{References}

1. Bock F, König Y, Kruse F, Baier M, Cursiefen C. Bevacizumab (Avastin) eye drops inhibit corneal neovascularization. Graefes Arch Clin Exp Ophthalmol. 2008;246(2):281-284.

2. DeStafeno JJ, Kim T. Topical bevacizumab therapy for corneal neovascularization. Arch Ophthalmol. 2007;125(6):834-836.

3. Doctor PP, Bhat PV, Foster CS. Subconjunctival bevacizumab for corneal neovascularization. Cornea. 2008;27(9):992-995.

4. Bahar I, Kaiserman I, McAllum P, Rootman D, Slomovic A. Subconjunctival bevacizumab injection for corneal neovascularization in recurrent pterygium. Curr Eye Res. 2008;33(1):23-28.

5. Besharati MR, Manaviat MR, Souzani A. Subconjunctival bevacizumab injection in treatment of pterygium. Acta Med Iran. 2011;49(3): 179-183.

6. Enkvetchakul O, Thanathanee O, Rangsin R, Lekhanont K, SuwanApichon O. A randomized controlled trial of intralesional bevacizumab injection on primary pterygium: preliminary results. Cornea. 2011; 30(11):1213-1218.

7. Fallah Tafti MR, Khosravifard K, Mohammadpour M, Hashemian MN, Kiarudi MY. Efficacy of intralesional bevacizumab injection in decreasing pterygium size. Cornea. 2011;30(2):127-129.

8. Saxena S, Vishwkarma K, Khattri M, Kishore P. Multiple subconjunctival bevacizumab for advanced primary pterygium. Ann Ophthalmol (Skokie). 2010;42 Spec No:28-30.

9. Teng CC, Patel NN, Jacobson L. Effect of subconjunctival bevacizumab on primary pterygium. Cornea. 2009;28(4):468-470.

10. Banifatemi M, Razeghinejad MR, Hosseini H, Gholampour A. Bevacizumab and ocular wound healing after primary pterygium excision. J Ocul Pharmacol Ther. 2011;27(1):17-21.

11. Galor A, Yoo SH, Piccoli FV, Schmitt AJ, Chang V, Perez VL. Phase I study of subconjunctival ranibizumab in patients with primary pterygium undergoing pterygium surgery. Am J Ophthalmol. 2010;149(6): 926-931. e2.

12. Mandalos A, Tsakpinis D, Karayannopoulou G, et al. The effect of subconjunctival ranibizumab on primary pterygium: a pilot study. Cornea. 2010;29(12):1373-1379.

13. Razeghinejad MR, Hosseini H, Ahmadi F, Rahat F, Eghbal H. Preliminary results of subconjunctival bevacizumab in primary pterygium excision. Ophthalmic Res. 2010;43(3):134-138.

14. Shenasi A, Mousavi F, Shoa-Ahari S, Rahimi-Ardabili B, Fouladi RF. Subconjunctival bevacizumab immediately after excision of primary pterygium: the first clinical trial. Cornea. 2011;30(11):1219-1222. 
15. Fallah MR, Khosravi K, Hashemian MN, Beheshtnezhad AH, Rajabi MT, Gohari M. Efficacy of topical bevacizumab for inhibiting growth of impending recurrent pterygium. Curr Eye Res. 2010;35(1): $17-22$.

16. Lekhanont K, Patarakittam T, Thongphiew P, Suwan-Apichon O, Hanutsaha P. Randomized controlled trial of subconjunctival bevacizumab injection in impending recurrent pterygium: a pilot study. Cornea. 2012;31(2):155-161.

17. Wu PC, Kuo HK, Tai MH, Shin SJ. Topical bevacizumab eyedrops for limbal-conjunctival neovascularization in impending recurrent pterygium. Cornea. 2009;28(1):103-104.

18. Jin J, Guan M, Sima J, et al. Decreased pigment epithelium-derived factor and increased vascular endothelial growth factor levels in pterygia. Cornea. 2003;22(5):473-477.

19. Lee DH, Cho HJ, Kim JT, Choi JS, Joo CK. Expression of vascular endothelial growth factor and inducible nitric oxide synthase in pterygia. Cornea. 2001;20(7):738-742.

20. Lee JK, Song YS, Ha HS, et al. Endothelial progenitor cells in pterygium pathogenesis. Eye. 2007;21(9):1186-1193.
21. Mauro J, Foster CS. Pterygia: pathogenesis and the role of subconjunctival bevacizumab in treatment. Semin Ophthalmol. 2009;24(3): $130-134$.

22. Hosseini H, Nejabat M, Khalili MR. Bevacizumab (Avastin) as a potential novel adjunct in the management of pterygia. Med Hypotheses. 2007;69(4):925-927.

23. Mansour AM. Treatment of inflamed pterygia or residual pterygial bed. Br J Ophthalmol. 2009;93(7):864-865.

24. Ferrara N, Damico L, Shams N, Lowman H, Kim R. Development of ranibizumab, an anti-vascular endothelial growth factor antigen binding fragment, as therapy for neovascular age-related macular degeneration. Retina. 2006;26(8):859-870.

25. Folk JC, Stone EM. Ranibizumab therapy for neovascular age-related macular degeneration. N Engl J Med. 2010;363(17):1648-1655.

26. VanRoekel RC, Bower KS, Burka JM, Howard RS. Anterior segment measurements using digital photography: a simple technique. Optom Vis Sci. 2006;83(6):391-395.
Clinical Ophthalmology

\section{Publish your work in this journal}

Clinical Ophthalmology is an international, peer-reviewed journal covering all subspecialties within ophthalmology. Key topics include: Optometry; Visual science; Pharmacology and drug therapy in eye diseases; Basic Sciences; Primary and Secondary eye care; Patien Safety and Quality of Care Improvements. This journal is indexed on

Submit your manuscript here: http://www.dovepress.com/clinical-ophthalmology-journal

\section{Dovepress}

PubMed Central and CAS, and is the official journal of The Society of Clinical Ophthalmology (SCO). The manuscript management system is completely online and includes a very quick and fair peer-review system, which is all easy to use. Visit http://www.dovepress.com/ testimonials.php to read real quotes from published authors. 